\title{
ARISTÓTELES EN CUATRO CONSEJEROS DE MAGNATES: CARTAGENA, VALERA, MARGARIT Y CHINCHILLA*
}

\author{
Barry Taylor \\ British Library \\ barry.taylor@bl.uk
}

\section{Introducción}

Aunque existía en la Edad Media el concepto del rey sabio, que combinaba fortitudo y sapientia (bien como sabiduría moral o erudición), en la práctica era frecuente que se dividieran estas funciones, cabiendo al monarca la fortaleza y la sabiduría a su consejero. En palabras de Juan de Gales:

Quod si forte illiteratus est princeps consiliis litteratorum eum regi necesse est. Unde a sacerdotibus iubet accipere exemplar legis .i. a viris catholicis et ecclesiasticis: sicut exponit Elynardus ${ }^{1}$.

Y según la traducción medieval catalana:

E si per ventura lo rey és sens letres, necessari li és que $\cdot s$ regescha amb los concells dels hòmens letrats. E por ço és menat, segons que posa Elimandus, que l'exemplar de la ley sia pres dels sacerdots, ço és, dels hòmens ecclesiàstichs².

Así nació el género del speculum principis, que se puede definir como un tratado de vicios y virtudes que atañe al monarca, pero también a un destinatario más genérico:

* Este trabajo se publica en colaboración con el proyecto de investigación Alfonso de Cartagena. Obras Completas FFI 2014-55902-P y FFI 2017-84858-P (MINECO y MICINN, Gobierno de España).

${ }^{1}$ Juan de Gales, Breviloquium, parte 1, cap. 1 «De prudentia», f. 246r. [En línea]. Enlace: <http:// bvpb.mcu.es/es/consulta/registro.cmd?id=449416>.

${ }^{2}$ Joan de Gal.les, Breviloqui, ed. de Norbert d'Ordal, Barcelona, Barcino, 1930, p. 68. 
Onde pues que tantos males nascen de la locura, todos los omes deven seer apercibidos, señaladamente los nobles señores que non deven consentir a los locos llegar a los sus consejos de poridat ${ }^{3}$.

El presente estudio se centra en siete obras de cuatro escritores acerca de la formación moral del príncipe o magnate. Los textos son el Doctrinal de caballeros de Alfonso de Cartagena de hacia 1444; cuatro obras de Diego de Valera creadas en un lapso de cuatro decenios, especialmente el Doctrinal de príncipes, dedicado a Fernando de Aragón; también dedicada al futuro Rey Católico, la Corona regum de Joan Margarit, compuesta hacia 1468; y la Exhortación o información de buena y sana doctrina compilada por Pedro de Chinchilla hacia 1467 para el joven Alfonso XII.

En todas estas obras se aprecia la presencia de Aristóteles, pero tal y como se demostrará aquí el conocimiento de las obras del Filósofo por parte de estos autores es notablemente diverso.

\section{Alfonso de Cartagena y Grosseteste}

Cartagena escribió el Doctrinal de caballeros «a instancia y ruego del señor don Diego Gómez de Sandoval, conde de Castro y de Denia» (p. 55) ${ }^{4}$. Su fuente principal son las Siete Partidas: en efecto, la mise en texte del Doctrinal se modela sobre la de los textos jurídicos, con títulos, «rubricelas» y leyes.

Noel Fallows, en su modélica edición, ha identificado siete pasajes en que Cartagena cita a Aristóteles:

\begin{tabular}{|l|l|l|}
\hline $\begin{array}{l}\text { Doctrinal de } \\
\text { caballeros, p. 63, n. 2 } 2\end{array}$ & $\begin{array}{l}\text { El esfuerzo discreto y la esfor- } \\
\text { zada discreción son de loar en } \\
\text { los caballeros, y no el presun- } \\
\text { tuoso atrevimiento ni la atrevi- } \\
\text { da presunción. }\end{array}$ & $\begin{array}{l}\text { Fallows: «Las dos } \text { [en lo suce- } \\
\text { frases del Doctrinal de los ca- } \\
\text { falleros se basan en la Ética a } \\
\text { Nicómaco». }\end{array}$ \\
\hline
\end{tabular}

${ }^{\text {a }}$ En el presente artículo el texto aristotélico se cita según el sistema de August Immanuel Becker (1785-1871); utilizado por ej. en Aristóteles, Ética Nicomáquea; Ética Eudemia, tr. de Julio Pallí Bonet, Madrid, Gredos, 1985. Como se indica abajo, es de suponer que Cartagena manejaba la traducción de Grosseteste, que se puede leer en: Aristoteles latinus, dirección general L. Minio-Paluello, 26:1-3, 5 tomos, Leiden, Brill, 1971-74; dicha edición utiliza el sistema Becker.

\footnotetext{
${ }^{3}$ Maestre Pedro, Libro del consejo e de los consejeros, ed. de Barry Taylor, San Millán de la Cogolla, Cilengua, 2014, pp. 155-156; más ejemplos en la p. 68.

${ }^{4}$ Alonso de Cartagena, «Doctrinal de los caballeros», en Tratados militares, ed. de Noel Fallows, Madrid, Ministerio de Defensa, 2006, pp. 53-444.
} 


\begin{tabular}{|l|l|l|}
\hline p. 65, n. 28 & $\begin{array}{l}\text { Y el Filósofo dice que en aque- } \\
\text { llas tierras hubo hombres más } \\
\text { fuertes donde la fortaleza fue } \\
\text { loada y la cobardía denostada }\end{array}$ & $3.8 .1-3$ \\
\hline p. 167, n. 459 & $\begin{array}{l}\text { Pura y estrecha justicia, que lla- } \\
\text { ma el Filósofo Comutativa... }\end{array}$ & 5.4 \\
\hline p. 167, n. 461 & $\begin{array}{l}\text { La justicia que llama el Filósofo } \\
\text { Distributiva... }\end{array}$ \\
\hline p. 175, n. 480 & $\begin{array}{l}\text { Los caballeros ... se deleitan } \\
\text { mucho en recordarse de la proe- } \\
\text { za que hicieron. Ca la memo- } \\
\text { ria de la virtud, según Filósofo } \\
\text { dice, muy deleitable es }\end{array}$ & $10.8-9$ \\
\hline p. 266, n. 815 & $\begin{array}{l}\text { Onde el Filósofo dice que en } \\
\text { los torneos y en las pruebas de } \\
\text { las armas no se parece cuál es } \\
\text { es el fuerte, ca la fortaleza ver- } \\
\text { dadera en los hechos terribles y } \\
\text { peligrosos de muerte que por la } \\
\text { república se hacen se conoce }\end{array}$ & $3.8 .8-9$ \\
\hline p. 322, n. 1042 & $\begin{array}{l}\text { Y como esta materia [la amis- } \\
\text { tad] trata por extenso Aristóte- } \\
\text { les en el Octavo de las Éticas... }\end{array}$ & \\
\hline
\end{tabular}

En suma, Cartagena cita correctamente el contenido de la Ética. No suele dar libro y capítulo, pero no hay razones para dudar que haya conocido el texto de Aristóteles (presumiblemente en la versión latina de Grosseteste revisada por Moerbeke).

El mismo Cartagena había aprovechado la obra de Aristóteles en una producción anterior, el Memoriale virtutum, un compendio moral que, a pesar de dirigirse al príncipe Duarte de Portugal, no hace mención del estamento real. En esta obra la deuda con Aristóteles es total:

Todo lo que sin actor escripto aquí leyeres, al Filósofo e a los glosadores d'él (señaladamente a Thomás) atribuye las palabras que para el ayuntar de la orden o más claro entender pensé traer... ${ }^{5}$

\footnotetext{
${ }^{\mathrm{b}}$ Aristóteles obviamente no habla de los torneos, pero sí contrasta la fortaleza de los atletas con la de los soldados del estado.

${ }^{5}$ El «Memorial de virtudes»: la traducción castellana del «Memoriale virtutum» de Alfonso de Cartagena, ed. de Mar Campos Souto, Burgos, Instituto Municipal de Cultura, 2004, p. 196.
} 


\section{Joan Margarit y Bruni}

Para su Corona regum Joan Margarit adoptó, por su parte, la estructura alegórica de una exégesis moral de las joyas que forman la corona del rey ${ }^{6}$. El autor también escribió una obra perdida de naturaleza análoga, Sedes regum o Epistola seu libellus de educatione Ferdinandi Aragoniae principis (I, 8). La editora del texto, Segarra, ha identificado todas sus fuentes, y concluye: «La Ėtica constitueix el punt de partença del pensament del nostre autor en gairebé tots els capítols de la Corona regum. És font troncal» (I, 65). Se sabe por el inventario de su biblioteca que Margarit poseía el De animalibus, la Física (comentada por Tomás de Aquino), la Económica y la Política (traducidas por Bruni), además de dos specula de tradición aristotélica, el De rege de Aquino y el De regimine principum de Gil de Roma (I, 63)7.

Margarit cita unas setenta veces a «Aristoteles» (y no «el Filósofo») (II, 343-4); entre estas citas figuran cuarenta y cuatro a la Ética. En el presente estudio solo hay espacio para examinar unos pocos ejemplos.

En general, Margarit suele resumir el texto de Aristóteles en vez de transcribirlo. La frase «colligi potest» demuestra claramente su método:

Vnde Aristoteles in principio secundi libri Ethicorum refert quod ad intelligentiam rerum spiritualium et virtutum intellectualium opus erat tempore et experientia et ideo praemittit tractare de moralibus virtutibus, quae consistunt in usu atque experientia... (p. 164 [14]).

D'aquí que Aristòtil en el principi del llibre segon de l'Ètica [EN 2.1103a151103a30] afirma que a la comprensió dels afers espirituals i de les virtuts intel·lectuals els calia temps i experiència, i per això començà a tractar primerament de les virtuts morals, que consisteixen en l'ús i en l' experiència...

Dicimus quod istam uirtutem debent maxime uenerari et sequi principes, quoniam, si intemperatus princeps est, quasi iumento irrationabili comparandus est, prout clare colligi potest ex dictis Aristotelis in libro tertio Ethicorum. (p. $252[6])$.

Diem que els prínceps han de venerar sobretot aquesta virtut [temprança] i seguir-la, perque si un príncep no és atemperat, hom l'haurà de comparar

\footnotetext{
${ }^{6}$ Joan Margarit, Corona regum, ed. de M. Isabel Segarra, 2 vols, Belcaire d'Empordà, Vitel·la, 2008.

${ }^{7}$ Segarra (I, 63), quien sigue a Tate, no encuentra la Ética en el inventario de la biblioteca de Margarit, en Documentos para la historia de la imprenta y librería en Barcelona (1474-1553), ed. de José M. ${ }^{a}$ Madurell Marimón y Jorge Rubió y Balaguer, Barcelona, Gremios de Editores, de Libreros y de Maestros Impresores, 1955, doc. 274 (pp. 488-500).
} 
gairebé a un animal irracional, com pot inferir-se clarament de les paraules d' Aristòtil en el llibre tercer de l’Ètica [3.1119a25-1119b15].

\section{Pedro de Chinchilla y Aristóteles vía Castrogeriz}

Pedro de Chinchilla, poco antes, había compuesto dos obras dirigidas a la formación moral del noble ${ }^{8}$. En 1466 escribió la Carta y breve compendio para Rodrigo Alfonso, IV conde de Benavente. Como es usual en los specula principis, las virtudes generales se dirigen a las autoridades políticas: «Capítulo xii, de los grandes príncipes y señores que tienen cargo de regir pueblos, cómo deven ser cuidosos en los governar por amor» (p. 191). En esta obra Chinchilla se refiere una sola vez a Aristóteles: «Y en fin d'ello, están puestas la cuatro virtudes cardinales, segúnd d'ellas escrivió el grand filósofo Aristótiles» (p. 165), sección que parece faltar en el único manuscrito conservado.

Un año después, Chinchilla escribió para el joven Alfonso XII la Exhortación o información de buena y sana doctrina. Aquí el nombre del Filósofo aparece con frecuencia; sin embargo, según ha demostrado el editor del texto, David Nogales Rincón, Chinchilla no bebe directamente en el texto de la Ética, sino que deriva todas (o casi todas) sus citas de Gil de Roma, que probablemente leía en la traducción de Castrogeriz (pp. 83-86, 89-91).

\section{Diego de Valera y Aristóteles vía las Auctoritates Aristotelis}

Diego de Valera (1412-1488), en fin, compuso cuatro obras de regimine principum: el Espejo de la verdadera nobleza (c. 1441) para Juan II; el Breviloquio de virtudes (c. 1447-1448) para don Rodrigo Pimentel, conde de Benavente; la Exhortación de la paz (c. 1448) para Juan II de Castilla; y el Doctrinal de príncipes (c. 1474-1476) para Fernando el Católico ${ }^{9}$. Las cuatro obras son muy similares, por lo que se refiere a su argumento general. Tres de ellas (pero no el Espejo) comparten ciertas fuentes. Para citar solo un ejemplo, una sentencia de Cicerón (De officiis, I.89) se emplea en tres ocasiones:

\footnotetext{
${ }^{8}$ Pedro de Chinchilla, Carta y breve compendio y Exhortación o información de buena y sana doctrina, ed. de David Nogales Rincón, Valencia, Universitat de València, 2017.

${ }^{9}$ Diego de Valera, en Prosistas castellanos del s. XV, ed. de Mario Penna, BAE, 116, Madrid, Atlas, 1959: Espejo de verdadera nobleza, pp. 89-116; Breviloquio de virtudes, pp. 147-160; Doctrinal de príncipes, pp. 173-202; Andrea Baldissera, «La Exhortación de la paz di Diego de Valera (edizione critica)», en Guerra e pace nel pensiero del Rinascimento, Atti del XXV Convegno Internazionale (ChancianoPienza 14-17 luglio 2003), ed. de Luisa Secchi Tarugi, Firenze, Franco Cesati, 2005, pp. 467-491 (también cito la paginación de la edición de Penna, pp. 77-87).
} 
Breviloquio 153b nota 27: $\mid$ Exhortación 82b/483: como $\mid$ Doctrinal 185b: Que dise Tulio, en el segundo de dize Tullio: Optandum est Tullio: De desear es que Oficios: De desear es que enim ut hi qui presunt rei los que la cosa pública golos que goviernan la cossa publice legum similes sint, viernan, sean semejantes a pública sean semejantes a que ad puniendum non ira- las leyes, las quales a punir las leyes, las quales no por cundia sed equitate ducuntur o castigar, no por ira, mas ira a punir o castigar se mue- Véase nota al margen: (p. por igualdat se mueven ven, mas por egualdat $87 \mathrm{~b} / 489)$ in quadam epistola

También se aprecia que solo cuando Valera escribe para el docto Juan II cita a Cicerón en latín. Da la referencia bibliográfica más correctamente en el Breviloquio e incorrectamente en la Exhortación.

Rodríguez-Velasco propuso que Valera había aprovechado la magnífica biblioteca de su mecenas, el conde de Benavente ${ }^{10}$. En este artículo quisiera argumentar que para sus citas de Aristóteles, Valera no fue directamente ad fontes, sino que echó mano de un éxito medieval, el florilegio Auctoritates Aristotelis ${ }^{11}$.

Las Auctoritates Aristotelis [en lo sucesivo, AA], redactadas en el s. XIII, son un epítome de las obras de varios autores clásicos, no exclusivamente Aristóteles: «Auctoritates Aristotelis, Senecae, Boethii, Platonis, Appulei Africani, Porphyrii et Gilberti Porretani». Se mantiene el orden original de los fragmentos y el proceso de extracción suele dar a las citas un carácter sentencioso que no necesariamente tenían en su contexto original. En palabras de Cuccia,

Frente al enorme beneficio proporcionado por los florilegios aristotélicos al poner a disposición de un importante número de académicos un conocimiento que fue completamente inaccesible durante siglos, debe considerarse como contraparte una desventaja significativa que es común a todos los florilegios: en general, al mostrar una doctrina parcializada y sintetizada en unas pocas frases muchas veces inconexas, tal tipo de compilación contribuyó a deformar el pensamiento de Aristóteles, tergiversando el sentido de algunas afirmaciones o, incluso, omitiendo pasajes importantes de sus obras $(182)^{12}$.

\footnotetext{
${ }^{10}$ Jesús D. Rodríguez Velasco, El debate sobre la caballería en el siglo xv. La tratadística caballeresca castellana en su marco europeo, Salamanca, Junta de Castilla y León, 1996, p. 247.

${ }^{11}$ Les Auctoritates Aristotelis. Un florilège médiéval, ed. de Jacqueline Hamesse, Philosophes médiévaux, 17, Louvain, Publications universitaires, 1974.

${ }^{12}$ Emiliano Javier Cuccia, «La recepción de las Auctoritates Aristotelis en la doctrina del sujeto de las virtudes morales de Juan Duns Escoto», en La compilación del saber en la Edad Media, ed. de María José Muñoz, Patricia Cañizares y Cristina Martín, Porto, Fédération Internationale des Instituts d'Études Médiévales, 2013, pp. 181-194.
} 
Aunque el incipit declara que se dirige a un doble público - «pro usu introductionis thematum ipsorum praedicatorum ad populum simul ac in artibus studere volentium»-se nota que el prólogo menciona solo los sermones.

En 1979, Olsen catalogó 26 florilegios de este tipo, conservados en manuscritos de los Ss. IX a XIII. La difusión europea de las $A A$ era impresionante: en el momento de preparar su edición, Hamesse conocía 153 testimonios, y en 1994 añadió 227 más $^{13}$. Autores del prestigio de Alejandro de Hales, Buenaventura y Duns Escoto echaron mano de esta compilación.

El conocimiento de las $A A$ en España pasó desapercibido hasta que $\mathrm{Mu}-$ ñoz publicó un estudio de nueve manuscritos hoy existentes en bibliotecas de España ${ }^{14}$. La investigadora indica dos problemas que oscurecen la transmisión de las $A A$ : «es posible observar numerosas diferencias y variaciones entre ellos tanto en el título dado al florilegio, en los contenidos que ofrecen y en la atribución de la autoría» (39).

Si la presencia de las $A A$ en España está bien establecida, su utilización por parte de los autores españoles permanece todavía en la oscuridad. Muñoz ha demostrado que las $A A$ están compendiadas en el Vade Mecum, florilegio compilado en el entorno del conde de Haro. En un estudio dedicado a una obra maestra española, Ruiz Arzálluz también puso al descubierto el uso que hace de las $A A$ el primitivo autor de la Celestina ${ }^{15}$.

Las citas aristotélicas en la obra de Valera se exponen en la tabla siguiente:

\begin{tabular}{|l|l|l|}
\hline Espejo & $A A$ & $\begin{array}{l}\text { Penna } \\
\text { (nota) } \\
\text { sugiere que } \\
\text { 'posteriores' } \\
\text { onde dize: Nobles parescen ser aquellos cuyos proge- } \\
\text { nitores virtuosos fueron ricos } \\
\text { Políticos } 4.1 \\
\text { o bien Retó- } \\
\text { rica } 1.15\end{array}$ \\
\hline $\begin{array}{l}\text { 91b como Aristotiles dize en el primero de las Eticas, } \\
\text { capitulo quarto: Asi como una golondrina no faze ve- } \\
\text { rano, asi un acto de virtud no faze al onbre virtuoso, } \\
\text { mas conviene para lo ser larga continuación }\end{array}$ & 233.11 & \\
\hline
\end{tabular}

\footnotetext{
${ }^{13}$ Jacqueline Hamesse, «Les manuscrits des Parvi flores: une nouvelle liste des témoins», en Scriptorium, 48 (1994), pp. 299-322.

${ }^{14}$ María José Muñoz, «Los manuscritos de las Auctoritates Aristotelis conservados en España», en Les «Auctoritates Aristotelis», leur utilisation et leur influence, ed. de J. Hamesse y J. Meirinhos, Barcelona, Fédération Internationale des Instituts d'Études Médiévales, 2015, pp. 39-59.

${ }^{15}$ I. Ruiz Arzálluz, «El mundo intelectual del 'antiguo autor': las Auctoritates Aristotelis en la Celestina primitiva», en Boletín de la Real Academia Española, 76 (1996), pp. 265-283.
} 


\begin{tabular}{|c|c|c|}
\hline $\begin{array}{l}\text { 92b } \\
\text { El Filosofo en el tercero de las Eticas, seteno capitu- } \\
\text { lo, onde dize: Las obras fazen que las usa tal quales } \\
\text { ellas son }\end{array}$ & & \\
\hline $\begin{array}{l}\text { 92b el Filosofo en el primero de la Politicas, qu[]to ca- } \\
\text { pitulo, onde dize: Ninguna [] cosa que virtud y malicia } \\
\text { determin[] el libre y el siervo o el noble y el plebeo }\end{array}$ & 253.20 & \\
\hline $\begin{array}{l}\text { 93b por los actos virtuosos se deven dar las dignida- } \\
\text { des, segunt pone Aristotiles en el capitulo primero del } \\
\text { Regimiento de los Principes a Alixandre, e asimismo } \\
\text { en el quarto de las Eticas, capitulo primero, onde dize } \\
\text { que el honor es galardon de la virtud, y por ende solo } \\
\text { a los virtuosos deve ser dado }\end{array}$ & 237.68 & \\
\hline $\begin{array}{l}\text { 94a Aristotiles en el quarto de las Eticas, capitulo } \\
\text { quinto, onde dize: que a la virtud conplida no le puede } \\
\text { ser fecho devido honor }\end{array}$ & 237.70 & \\
\hline $\begin{array}{l}\text { 94a al medio en el qual esta la virtud, segunt dize Aris- } \\
\text { totiles en el primero de las Eticas, capitulo noveno }\end{array}$ & & \\
\hline $\begin{array}{l}\text { 94b como quiera que este medio sea muy dificile de } \\
\text { guardar, segunt dize Aristotiles en el Regimiento de } \\
\text { los Principes a Alixandre, capitulo primero }\end{array}$ & & \\
\hline $\begin{array}{l}\text { 95a el Filosofo en el primero de las Politicas, capitu- } \\
\text { lo quarto, onde dize: Ninguna otra cosa que virtud e } \\
\text { malicia determinaron los libres e siervos e nobles e } \\
\text { plebeos }\end{array}$ & & \\
\hline $\begin{array}{l}\text { 100b el Filosofo en el primero de las Politicas, capi- } \\
\text { tulo quarto: ninguna otra cosa que virtud y malicia } \\
\text { determinaron el libre y el siervo y el noble y el plebeo }\end{array}$ & & \\
\hline $\begin{array}{l}101 \text { la virtud consiste en el animo }{ }^{c} \text {, segunt dize Aris- } \\
\text { totiles en el segundo de las Eticas, capitulo quinto }\end{array}$ & $\begin{array}{l}235.38 \text { omnis virtus } \\
\text { constitit in medio }\end{array}$ & \\
\hline $\begin{array}{l}114 \text { NOTA de tres vidas es fecha mencion por el Fi- } \\
\text { losofo en el tercero de las Eticas, conviene a saber: } \\
\text { volubtuosa, civil o politica, e contemplativa }\end{array}$ & & \\
\hline $\begin{array}{l}\text { Breviloquio } \\
\text { 148a } \\
\text { Virtud en común, segund el Filósofo: «Est abitus } \\
\text { electivus in medio consistens quo ad nos» } \\
\text { NOTA 153a 17: En el segundo de las éticas: Virtud es } \\
\text { ábito electivo consistente en el medio, quanto a nos } \\
\text { Repetido en } \\
\text { Doctrinal 190b: por el Philósopho virtud es un ábito } \\
\text { voluntario, en medio consistiente, quanto a nos }\end{array}$ & $\begin{array}{l}\text { 235.42: } \\
\text { Virtus est habitus } \\
\text { electus in mente } \\
\text { consistens quo } \\
\text { ad nos declarata ra- } \\
\text { tione ut utique sa- } \\
\text { piens determinabit }\end{array}$ & $\begin{array}{l}E N \text { B2 } \\
1106 \mathrm{~b} 36- \\
1107 \mathrm{a} 2\end{array}$ \\
\hline
\end{tabular}

${ }^{\mathrm{c}}$ Animo es un error de copia por medio, como se colige de la fuente latina. 


\begin{tabular}{|c|c|c|}
\hline $\begin{array}{l}\text { Exhortación 81a/481: el Filosofo: justitia est virtus } \\
\text { perfecta, iusticia est omnis virtus, iusticia est precla- } \\
\text { rissima virtus } \\
\text { NOTA } 31 \text { (p 86) in quinto Ethicorum } \\
\text { Repetido en } \\
\text { Doctrinal 195b: el Philosopho en el quarto de las Eti- } \\
\text { cas: la justicia ... es virtud perfecta, e que es toda } \\
\text { virtud e que es muy clara virtud }\end{array}$ & & \\
\hline $\begin{array}{l}\text { Doctrinal } 174 \text { el Philosopho en el quinto de las Eticas } \\
\text { dize que el rey es ley animada e regla por donde sus } \\
\text { pueblos se han de regir }\end{array}$ & & \\
\hline $\begin{array}{l}\text { 178b e Aristotiles a Alixandre desia: Ninguno sea de } \\
\text { tus nobles que tu liberalidad no sienta }\end{array}$ & & \\
\hline $\begin{array}{l}\text { 181a Aristotiles: el reino governado sin sabiduria no } \\
\text { puede luengamente durar }\end{array}$ & & \\
\hline $\begin{array}{l}\text { 182b dise el Philosopho: Alli son los onbres fuertes, } \\
\text { donde los fuertes son loados }\end{array}$ & & EN 3.8.1-3 \\
\hline $\begin{array}{l}\text { 183b el Philosopho en el quinto de las Heticas, donde } \\
\text { dice que en tienpo de tirano pocos virtuosos se fallan, } \\
\text { porque a exemplo del rey todo el reino se compone }\end{array}$ & & \\
\hline $\begin{array}{l}\text { 187a Y el Philosopho: Ninguna cosa forçosa puede } \\
\text { ser perpetua }\end{array}$ & & \\
\hline $\begin{array}{l}\text { 188a el Philósopho en el quinto de las Eticas dise que } \\
\text { la justicia es entera virtud, y el contrario della es aca- } \\
\text { bado mal. E por eso no puede luegamente durar el } \\
\text { reino donde fallesce justicia }\end{array}$ & 238.85 & \\
\hline $\begin{array}{l}\text { 188b Segun SantoThomas ... e Seneca ... y Egidio de } \\
\text { Roma ... y el Philosopho en el tercero de las Politi- } \\
\text { cas, la diferencia entre el rey y el tirano es esta: que el } \\
\text { rey tiene las armas para defender la republica, el rey } \\
\text { para ofenderla... }\end{array}$ & & \\
\hline $\begin{array}{l}\text { 189a el Philosopho en el octavo de las Politicas dise } \\
\text { qu'el mal rey es tirano e qu'el buen rey se deve aver a } \\
\text { los subditos como el pastor a las ovejas }\end{array}$ & & \\
\hline $\begin{array}{l}194 \text { a la qual [magnanimidad] segunt el Philosopho } \\
\text { en el tercero de las Ethicas, conviene ninguna cosa } \\
\text { temer, salvo los torpes, las cosas prosperas e adversas } \\
\text { pasando con egual cara }\end{array}$ & & \\
\hline $\begin{array}{l}\text { 195a el Philósopho dise qu'el honor es galardon de } \\
\text { la virtud }\end{array}$ & $237.68-9$ & \\
\hline
\end{tabular}




\begin{tabular}{|c|c|c|}
\hline $\begin{array}{l}\text { 195a: según el Philósopho, en el quarto de las Éthi- } \\
\text { cas, la justicia tiene quatro partes, es a saber: legal, } \\
\text { particular, comutativa, distributiva. Legal es la justi- } \\
\text { cia escripta, de la qual dise el Philósopho, que es vir- } \\
\text { tud perfecta, e que es toda virtud e que es muy clara } \\
\text { virtud. }\end{array}$ & $\begin{array}{l}\text { 239.89-91: Du- } \\
\text { plex est justitia, } \\
\text { scilicet totalis et } \\
\text { partialis. Partia- } \\
\text { lis est duplex, } \\
\text { scilicet commuta- } \\
\text { tiva et distributiva. } \\
\text { Commutativa est } \\
\text { duplex, scilicet } \\
\text { voluntaria et non } \\
\text { voluntaria. Non } \\
\text { voluntaria est du- } \\
\text { plex, scilicet oculta } \\
\text { et manifesta... }\end{array}$ & EN 5 \\
\hline $\begin{array}{l}\text { Doctrinal } 197 \mathrm{a}, \mathrm{n} 4 \\
\text { Dos maneras son de derecho: una es natural, otra es } \\
\text { legal. Derecho natural es aquel que en todos los on- } \\
\text { bres tiene egual poderío, así como la justa defensa } \\
\text { que a todo ome es premissa. Derecho legal es el dere- } \\
\text { cho escripto. El qual dispone las cosas según la diver- } \\
\text { sidat de los tienpos e lugares e calidat de los onbres } \\
\text { lo requiere, segunt el Philósopho lo nota en el quinto } \\
\text { de las Héticas }\end{array}$ & $\begin{array}{l}\text { 239:98-99: Duplex } \\
\text { est jus, scilicet } \\
\text { legale et naturale. } \\
\text { Naturales est quod } \\
\text { apud omnes habet } \\
\text { eandem potentiam, } \\
\text { legale autem insti- } \\
\text { tutum est a lege }\end{array}$ & $\begin{array}{l}\text { EN E10, } \\
1134 \mathrm{~b} 18-21\end{array}$ \\
\hline $\begin{array}{l}\text { 199a Tres maneras son de bienes segunt el Philóso- } \\
\text { pho en el sesto de las Eticas, es a saber: bienes del } \\
\text { anima, bienes del cuerpo, bienes de fuera, bienes de } \\
\text { fuera venientes }\end{array}$ & & \\
\hline $\begin{array}{l}\text { 199b Segun el Philósopho en el primero de la Metha- } \\
\text { fisica, la sapiencia es ciencia de las muy altas causas } \\
\text { primeras }\end{array}$ & 115.11 & \\
\hline $\begin{array}{l}\text { 202a el Philósopho en el octavo de las Eticas pone } \\
\text { tres maneras de amistança, es a saber: provechosa, } \\
\text { deleitable, honesta }\end{array}$ & $\begin{array}{l}\text { 243.143 Tripliciter } \\
\ldots\end{array}$ & EN 8 \\
\hline $\begin{array}{l}\text { 202a Aristótiles, en el undécimo de la Methaphísi- } \\
\text { ca dise qu'el primero movedor, es a saber Dios, es } \\
\text { fasedor }\end{array}$ & $\begin{array}{l}\text { 137:264 primus } \\
\text { motor ... }\end{array}$ & Met \\
\hline
\end{tabular}

Como se aprecia por esta tabla, ha sido posible rastrear 14 de las 31 citas aristotélicas de Valera en las $A A$. Dada la variedad de contenido que Muñoz identifica entre los testimonios de las $A A$, es posible que Valera manejara otra versión que le facilitara incluso más citas. Mosén Diego habría podido complementar sus lecturas de las $A A$ con material aristotélico extraído de autores como Gil de Roma, a quien menciona al menos en tres ocasiones (188a, 191a, 193b). 


\section{Balance}

El propósito de este estudio no ha sido alabar a aquellos autores humanistas que van ad fontes y leen las obras de Aristóteles en su integridad y denostar a los escritores medievales de segunda clase que trabajan con fuentes secundarias. Como muy bien demostraron Starnes y Talbert en 1955, los mayores genios del Renacimiento inglés hacían uso de los florilegios ${ }^{16}$.

La España del s. XV se puede contar entre las culturas que participaron en lo que Fumaroli calificó de «retórica de las citaciones» ${ }^{17}$. Considero que los escritores medievales disponían de un abanico de métodos para acercarse a las auctoritates, utilizando (i) el texto original de primera mano, (ii) de segunda mano a partir de un texto intermedio que lo cita, vía epítome, o vía florilegio (de autor o temático).

Con casi toda seguridad, Cartagena y Margarit acudieron y tuvieron acceso al texto íntegro latino de Aristóteles. Margarit poseía otras obras aristotélicas traducidas por Bruni, y es de suponer que tenía también su versión de la Ética ${ }^{18}$ Cartagena, como es archisabido, rechazaba la versión bruniana y habría manejado la versión más antigua de Grosseteste/Moerbeke ${ }^{19}$. Valera utiliza las $A A$. Chinchilla conoce a Aristóteles a través de Gil de Roma, traducido por Castrogeriz.

De nuestros escritores, Valera es el que tiene más acentuado el gusto por acumular sentencias ajenas, hábito quizás promovido por el uso del codex excerptorius, libro de notas en que el alumno (y después escritor) reunía bajo temas sentencias extraídas de sus lecturas ${ }^{20}$. Conviene citar este pasaje del Doctrinal:

${ }^{16}$ DeWitt T. Starnes y Ernest William Talbert, Classical myth and legend in Renaissance dictionaries: a study of Renaissance dictionaries in their relation to the classical learning of contemporary English writers, Chapel Hill, University of North Carolina Press, [1955].

${ }^{17}$ L'Âge de l'éloquence: rhétorique et «res literaria» de la Renaissance au seuil de l'époque classique, Genève, Droz, 1980, pp. 445, 603-608.

${ }^{18}$ No existe ninguna edición moderna de la traducción bruniana que emplee el sistema Becker (véase nota a arriba). El texto se puede leer, por ejemplo, en S. Tho. super Ethica Aristo. Sancti Doctoris Thome Aquinatis in decem libros Ethicorum Aristotelis profundissima cōmentaria: cum triplici textus translatione: antiqua videlicet Leonardi aretini: necnon Joānis argyropili suis locis inserta. Nouissime post omnes impressiones vbique locorum excussas: collatis multis exemplaribus: per dominum fratrē Paulinum de Luca ordinis predicatorum adamussim recognita, etc. ff. 166. Per Lucantonium de Giunta: Venetijs, 1519. British Library, 1485, f. 9; digitalizado en: <https://books.google.co.uk/books?id=1BVlAAAAcAAJ\&pg $=\mathrm{PP} 5 \# \mathrm{v}=$ onepage $\& \mathrm{q} \& \mathrm{f}=$ false $>$.

${ }^{19}$ María Morrás, «Sic et non: en torno a Alfonso de Cartagena y los studia humanitatis», en Euphrosyne, 23 (1995), pp. 333-346; y véase la nota. a arriba.

${ }^{20}$ Iveta Nakládalová, «Sixteenth and seventeenth-century Spanish collections of brief forms and the ars excerpendi》, en Brief Forms in Medieval and Renaissance Hispanic Literature, ed. de Barry Taylor y Alejandro Coroleu, Newcastle-upon-Tyne, Cambridge Scholars Publishing, 2017, pp. 189-203. 
Deve el rey curar mucho de su fama, ca dise Séneca: Vuestros fechos e dichos la fama rescibe, por ende, ninguna cossa devés más curar. E San Gregorio: Cruel es quien menosprecia su fama. E Salamón: Mas vale buen nonbre que muchas riquesas (186b).

Se trata del estilo que Walter Ong denominó «rapsódico», o sea, que zurce los fragmentos para hacer un todo ${ }^{21}$. Se nota también en Valera la tendencia a alinear sus autoridades en secuencias, sin introducir su propia voz. Otros escritores usaban la frase «iuxta illud» («al lado de esto» o bien «en apoyo de esto») entre cita y cita.

Margarit utiliza el texto original de Aristóteles pero no reproduce sus palabras sino su sustancia. A veces se limita a remitir al lector al texto original. Chinchilla, por su parte, toma la estructura de la Exhortación de Gil de Roma, a quien sigue paso a paso.

La presencia de Aristóteles es mucho más reducida en el speculum principum de Cartagena. En el Doctrinal -a diferencia del Memoriale virtutum-el Filósofo sirve como mina de sentencias (introducidas por «ca» y «ende») o definiciones; la primera cita transcrita arriba y la última se refieren a secuencias más largas de la Ética.

Tres de nuestros escritores se autodenominan como compiladores (alias «copiladores»), a excepción de Margarit, que no utiliza el término:

con afanoso trabajo curé de actores que della trataron, no solamente leer, mas aun acopilar e ayuntar sus actoridades ... (Valera, Espejo, p. 89a).

delibré la presente obra componer ... no abtorisada de mi flaco juisio, mas de los claros ingenios de famosos abtores ... por que en breve compendio e llano estilo serviros pueda (Valera, Doctrinal, p. 173a).

e comoquier que he muy poca familiaridad con estas leyes, ... las recurrí superficialmente, y ayunté de ellas algunas ... Y las puse en esta breve compilación (Cartagena, p. 66).

E algo de lo qu'ellos dixeron por copiosas palabras e dulce elocuencia y en alto y elevado estilo, yo, un simple lego, siervo e vasallo vuestro, copilaré en breves capítulos (Chinchilla, p. 200) 2 у 3 .

${ }^{21}$ Walter J. Ong, Rhetoric, Romance, and Technology, Ithaca, Cornell University Press, 1971, caps. 
El efecto es el de un tópico de falsa humildad ${ }^{22}$, pero también puede ser una forma de orgullo. Cuando en el s. XIV Maestro Pedro escribe: «pugné en estudiar con grand femencia en muchos libros e ayunté razones e abtoridades de santos e sabios e fiz este libro» (p. 112), no está exhibiendo su vergonzosa falta de originalidad sino su orgullosa erudición. Y tal como los escritores que se han estudiado en las páginas precedentes, cuando decía que compilaba, decía la verdad.

\section{Conclusión}

Todas las obras que se han examinado en este artículo pueden verse como testimonios de la influencia de Aristóteles en la España del s. XV y ofrecen un paralelo con las primeras traducciones de sus textos al castellano, también fruto de este $\operatorname{siglo}^{23}$. El papel que desempeñaba el consejero de magnates coincidía con el del traductor: conectar al hombre de estado con la cultura de los antiguos.

Más de un siglo después, otro consejero de príncipes, Pedro de Ribadeneira, invocaba al Estagirita y a su comentador para expresar la influencia que el hombre de letras ejercía (o buscaba ejercer) sobre el hombre de estado:

El eruditísimo y gravísimo cardenal Gabriel Paleoto prueba admirablemente la necesidad que tienen todos los príncipes de consejo [...] La verdadera prudencia, no solo enseña a hacer por si lo que toca a cada uno por razón de su oficio, sino también a aprovecharse de los otros y pedirles consejo, lo cual es señal de ánimo dócil y blando y amigo de ser enseñado; y esta blandura y docilidad es parte de prudencia, como enseñan Aristóteles y Santo Tomás ${ }^{24}$.

Recibido: 23/05/2018

Aceptado: 10/11/2018

\footnotetext{
${ }^{22}$ Noel Hathaway, «Compilatio: from plagiarism to compiling», en Viator, 20 (1989), pp. 19-44.

${ }^{23}$ Se trata de las traducciones de la Ética por Carlos de Viana (Philobiblon BETA texid 1401) y Pedro Díaz de Toledo (texid 1902) y el Compendio de la ética Nicomaquea, ed. de Salvador Cuenca Almenar, Zaragoza, Prensas de la Universidad de Zaragoza, 2017 (cfr. texid 1294). [En línea]. Enlace: <http://bancroft.berkeley.edu/philobiblon/beta_en.html $>$.

${ }^{24}$ Pedro de Ribadeneira, Tratado de la religión y virtudes que debe tener el príncipe cristiano para gobernar sus estados, BAE, 60 (1868), capítulo XXIV, De la necesidad que tiene el príncipe de consejo.
} 


\section{$\cos \operatorname{sos}$}

\section{ARISTÓteles EN CUATRO CONSEJEROS DE MAGNATES: Cartagena, Valera, Margarit y Chinchilla}

RESUMEN: Se estudia la presencia de Aristóteles (principalmente la Ética Nicomáquea) en el Doctrinal de caballeros de Alfonso de Cartagena c. 1444; cuatro obras de Diego de Valera creadas en un lapso de cuatro decenios, especialmente el Doctrinal de príncipes dedicado a Fernando de Aragón, futuro Rey Católico; la Corona regum de Joan Margarit, compuesta hacia 1468, también dedicada a Fernando de Aragón, y la Exhortación o información de buena y sana doctrina compilada por Pedro de Chinchilla hacia 1467 para el joven Alfonso XII. Todos estos tratados de regimine principum utilizan el texto aristotélico, directamente o a través de florilegios, pero difieren en el modo de manejar sus fuentes.

Palabras Clave: Tradición clásica. Aristóteles. Ética Nicomáquea. Filosofía moral. Regimientos de príncipes.

\section{ARISTOTLE IN FOUR CONSEJEROS DE MAGNATES: \\ Cartagena, Valera, Margarit y Chinchilla}

AbStract: The presence of Aristotle (principally the Nicomachean Ethics) in the Doctrinal de caballeros of Alfonso de Cartagena c. 1444; four works by Diego de Valera created in the course of four decades especially the Doctrinal de principes for Fernando of Aragon, the future Catholic Monarch; the Corona regum of Joan Margarit, c. 1468 and also dedicated to Fernando; and the Exhortación o información de buena y sana doctrina compiled by Pedro de Chinchilla c. 1467 for the young Alfonso XII. All these treatises de regimine principum draw on Aristotle, either directly or via florilegia, and differ in their treatment of the text.

Keywords: Classical Tradition. Aristotle. Nicomachean Ethics. Moral Philosophy. Mirror of Princes. 